OCEAN 2017 - Aberdeen, $19^{\text {th }}$ to $22^{\text {nd }}$ June 2017

Pages 1-5

http://dx.doi.org/10.1109/OCEANSE.2017.8084824

http://archimer.ifremer.fr/doc/00427/53881/

(C) 2017 IEEE

\title{
The EGIM, a generic instrumental module to equip EMSO observatories
}

\author{
Lanteri Nadine ${ }^{1}$, Legrand Julien ${ }^{1}$, Moreau Bertrand ${ }^{1}$, Lagadec Jean-Romain ${ }^{1}$, Rolin Jean-Francois ${ }^{1}$
}

\begin{abstract}
:
The EGIM aims to set up a number of ocean locations where the same set of core variables, including temperature, conductivity, pressure, dissolved $\mathrm{O} 2$, turbidity, ocean currents, and passive acoustics, are measured homogeneously: using identical hardware, the same sensor references, the same qualification methods, the same calibration methods, the same data format and access, and the same maintenance procedures.
\end{abstract}

The EGIM provides all the services required to ensure the best measurement quality and long-term reliability in line with the Best Practices Handbook by FIXO3 and ESONET-EMSO Label, these services being sensor power distribution, time stamping, data storage and backup, protection against the environment and against fouling and bi-directional communication services...

The EGIM is flexible and matches all EMSO site and discipline specific requirements. Operating modes, power requirements, mechanical design, embedded software enable the EGIM to adapt to the various EMSO node configurations: mooring line, sea bed station, cabled or non-cabled and surface buoy. Its compact and its modularity covers an array of deployment scenarios including being able to accommodate new instruments. This will be a key point to the modularity, inter-operability and capacity of the future evolution of the system. Having the EGIM as the sole reference for all nodes is a crucial step towards standardization, increasing global reliability and reducing costs across EMSO.

Keywords : Europe, Instruments, Calibration, Metrology, Sea measurements, Oceans, Observatories 


\section{INTRODUCTION}

Developed within the frame of the European Union funded H2020 project "Emsodev", the EGIM, EMSO Generic Instrument Module, is designed to consistently and continuously measure parameters of interest for the science areas covered by EMSO, the European Multidisciplinary Seafloor and water column Observatory, now established as a European Research Infrastructure Consortium. This infrastructure collects a long term series of key parameters from a network of regional nodes deployed around Europe and provides accurate records of marine environmental changes.

\section{FROM ESONET TO THE ERIC EMSO}

\section{A. From ESONET to the ERIC EMSO}

The scientific plan established in the EC funded Network of Excellence ESONET of proposing a concerted European contribution to the fixed point monitoring of the ocean underlined the need to address parameters of interest for all the instrumented sites. The core parameters defined in [H. Ruhl and all 2011] [1] are called "generic" while the site specific instruments are supported by more disciplinary comities. This concept has been a major legacy of ESONET to EMSO permanent infrastructure, able to foster its networking momentum.

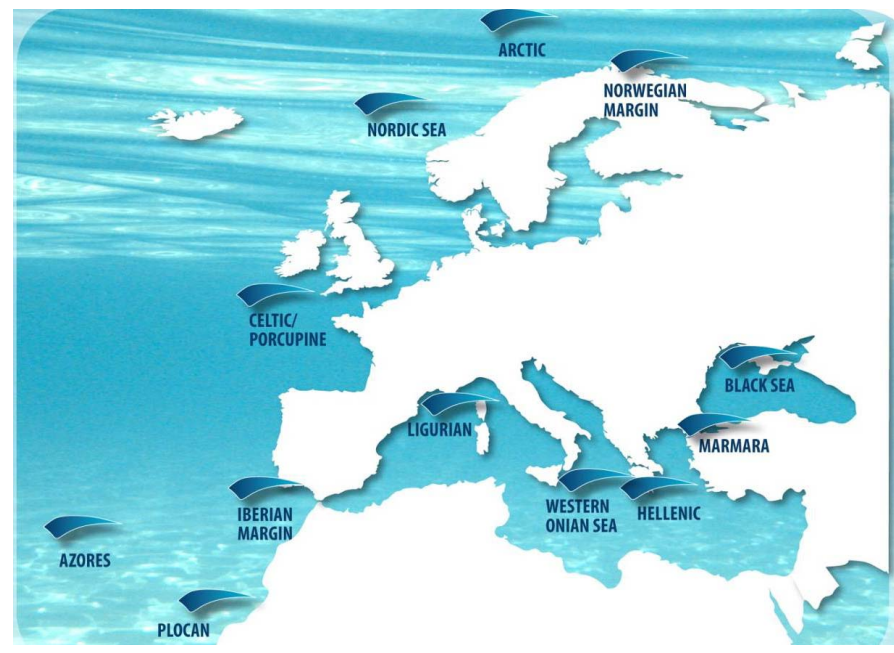

FIG. 1 EMSO NODES AROUND EUROPE

\section{B. EMSO, European Multidisciplinary Seafloor and water column Observatory}

The strength of EMSO lies in the fact that it is a distributed research infrastructure in the oceans of Europe, from the Arctic through the North Atlantic to the Mediterranean and the Black Sea. This array of observatory nodes allows for interactive, high-resolution; real-time coordinated observations of these interconnected ocean environments, and therefore monitoring processes at the regional level. The present operational status 
of EMSO nodes reflects the different development they have undergone according to the unavoidable local and regional conditions in terms of specific needs, technological skills of partners involved, budgetary constraints and building schedules. Basically although most of the nodes are at present operational and producing parameters data stream, EMSO still needs standardization and real interoperability both of the sensor, data acquisition equipment and of data flux and organization.

\section{EmsoDev, European project $H 2020$}

The European project H2020 (2015-2018) EmsoDev defined the state-of-the-art for open ocean observation technologies and expects to reinforce positioning in a rapidly growing global market. EmsoDev also provides practical experience in joint purchasing, using and benefiting from a sensor suite that is uniformly used across all the EMSO nodes, focusing on greatly improvement improved sensor integration to the provision of useful information. This practical experience includes user requirement updating, synthesis setting and implementing maintenance and calibration best practices, data handling, and most importantly a fully informed service activity that will ultimately be common to all sites. Sensor development will be accompanied by common calibration, data archiving, data processing, data access and third party development enabled by EMSO ERIC.

\section{THE EGIM}

\section{A. Objectives}

The development of a common instrumentation module EGIM will enhance the operational capacity of the EMSO nodes, cabled or stand alone, to collect a set of scientifically relevant data. EGIM development will implement common, standardized technologies according to architectures and interoperability reference studies performed during the EMSO preparatory phase and related projects, much which will ultimately be transferred to the industry via specifications in a tender process. The service-provision capacity of the nodes will be substantially increased, enabling EMSO Observatories to serve not only the science community, industries but also governmental organizations, industries and other stakeholders and even similar infrastructures.

\section{B. Measure variables homogeneously}

1) Same sensor references, positionning and hardware:

The first set of parameters has been selected for the EGIM prototype, taking mainly into account the sensor monitoring: temperature, conductivity, precise pressure, dissolved $\mathrm{O} 2$, turbidity, passive acoustics, ocean currents measurement.

This data can support the Global Ocean Observing System - Essential Ocean Variables concept, the Marine Strategy Framework Directive towards evaluating environmental status.

In addition to these core parameters, additional parameters are expected in the near future. The EGIM can host additional sensors, including Fluorescence /Chlorophyll-A, pH, Partial $\mathrm{CO} 2$ pressure, Partial $\mathrm{CH} 4$ pressure, Images, Seismometers,
$\mathrm{pH}$, seismic and photographic/video images or new sensors as long as their Technology Readiness Levels [2] is sufficient.

\section{2) Same qualification methods.}

During its lifetime, the EGIM will encounter the common oceanographic conditions: home base storage, transport, temporary storage on operation base, transit to operation site, deployment, underwater maintenance, and return to home base.

The conditions the equipment will be subjected to in each phase are the environmental parameters (in-situ natural environment and man built environment: temperature, air humidity, pressure, solar radiation) and the operation parameters (vibrations acceleration and mechanical shocks, thermal shocks).

Performing tests is of prime importance before planning any long term deployment at sea. The tests and calibration which are performed on the EGIM components comply with ESONET Label [3] recommendations. They are inspired by the document NF-XP X 10-812 [4]: Marine environment Oceanographic instrumentation - Guide for environmental tests.

TABLE 1: ENVIRONMENTAL FACTORS AND SEVERITIES

\begin{tabular}{|c|c|}
\hline Environmental factor & Severity \\
\hline Cold & $\begin{array}{l}\text { Storage : }-20^{\circ} \mathrm{C} / 72 \mathrm{~h} \\
\text { Sleeping mode: }-20^{\circ} \mathrm{C} / 16 \mathrm{~h} \\
\text { Running : }-2^{\circ} \mathrm{C}\end{array}$ \\
\hline Damp, saline atmosphere & $\begin{array}{l}\text { Storage: } 20^{\circ} \mathrm{C}, 50^{\circ} \mathrm{C} / 96 \mathrm{~h} \\
\text { Sleeping mode: } 20^{\circ} \mathrm{C}, 50^{\circ} \mathrm{C} / 8 \mathrm{~h}-5 \text { cycles - } \\
\mathrm{HR}=93 \% \\
\text { Running: } 50^{\circ} \mathrm{C} / 8 \mathrm{~h}-\mathrm{HR}=85 \%\end{array}$ \\
\hline Salt spray & $\begin{array}{l}\text { Storage: } 24 \mathrm{~h} / 24 \mathrm{~h}-6 \text { cycles } \\
\text { Running test after each cycle }\end{array}$ \\
\hline Solar radiation and heat & $\begin{array}{l}\text { Short term running: } 35^{\circ} \mathrm{C} \text { with solar radiation } \\
\text { Long term running: } 25^{\circ} \mathrm{C} \text { (Maximal in-situ } \\
\text { temperature) }\end{array}$ \\
\hline Vibrations & Sleeping mode, running test after each step \\
\hline Shocks & Mounted in the overall frame \\
\hline Platform Motion & Not relevant for underwater deployment \\
\hline $\begin{array}{l}\text { Electromagnetic } \\
\text { compatibility }\end{array}$ & Case by case \\
\hline Hydrostatic pressure & $\begin{array}{l}\text { According to the standard NFX } 10812 \text { class B, } \\
\text { Pservice }=625 \text { bars } \\
\text { Running and sleeping mode, } \\
1-\text { Ptest }=1,2 * \text { Pservice }-24 \mathrm{~h} \text { à }-2^{\circ} \mathrm{C} \\
2-\text { Ptest }=\text { Pservice: } 1 \mathrm{~h} \mathrm{Pe} / 1 \mathrm{~h} \text { Patm }-10 \\
\text { cycles }\end{array}$ \\
\hline $\begin{array}{l}\text { Thermal shock upon } \\
\text { immersion }\end{array}$ & Sleeping mode: $50^{\circ} \mathrm{C}, 10^{\circ} \mathrm{C} / 5 \mathrm{~s}$ \\
\hline Shocks due to swinging & Case by case in maintenance procedure \\
\hline
\end{tabular}



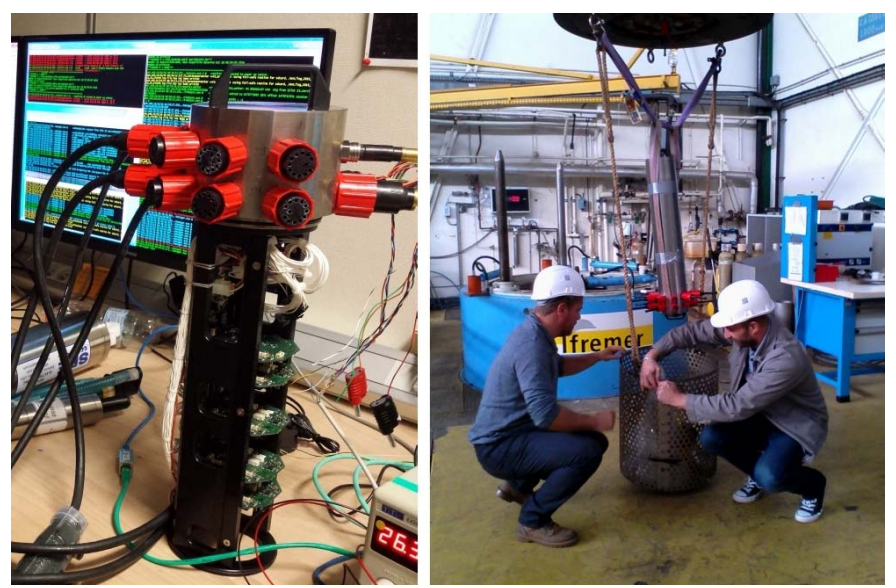

FIG.2 AND FIG. 3

EGIM QUALIFICATION TESTS

\section{3) Same calibration methods}

a) EC Projects of the marine community are providing inputs to improve the calibration practices useful for the EGIM.

FP6 ESONET NoE provided the ESONET Label which describes the generic sensor module and introduces metrology issues.

FP7 I3 JERICO, provided information about the best practices for sensor calibration of different types of sensors in a coastal oceanography context, it includes some parameters included as EGIM generic sensors.

FP7 I3 FixO3 has disseminated an updated version of its Handbook [5]. The discussions on parameters, calibration and quality control procedures in this handbook are relevant to EmsoDev. A FixO3 Label document was issued in August 2016. There is an agreement between the two projects to make the document available as an initial EMSO Label. It is envisaged to merge ESONET Label and FixO3 Label into a long lasting EMSO Label. EGIM recommendations will be an input to such Label.

H2020 ENVRIplus, is a project connecting Environment research infrastructures supported by the EC. A Work-package is devoted to metrology. It will address the link between calibration methods and international standards on key parameters at an international level. EMSO is involved in ENVRIPLUS as a major RI and can orientate some of the work to be performed, ENVRIplus may address shortfalls found in EGIM procedures. $\mathrm{pH}$ has already been mentioned as a common issue.

ESFRI ICOS Research Infrastructure project recommends the use of the IOCCP 2007 handbook. This document is the reference of $\mathrm{D} 3.1$ for the following parameters: $\mathrm{pH}$ and $\mathrm{CO} 2$. A new handbook on best practices is underway. Close relations with the ICOS marine community are kept thanks to FixO3 and ENVRIPLUS projects.

FP7 HYPOX addressed anoxic and hypoxic conditions in the sea. In particular Oxygen calibration and sensor intercomparisons were performed. The main conclusions on oxygen sensor calibration have been included in EGIM procedures.

\section{b) Metrology harmonization opportunities}

The European Commission is mindful of the strength for the European construction of innovative industry and European Research to provide common methods for metrology. EURAMET is the Regional Metrology Organization (RMO) of Europe. They coordinate the cooperation of National Metrology Institutes (NMI) in Europe in fields such as research in metrology, traceability of measurements to the SI units, international recognition of national measurement standards and related Calibration and Measurement Capabilities (CMC).

Two main tools to achieve these goals are the European Metrology Research Program (EMRP) and the European Metrology Program for Innovation and Research (EMPIR) with more than 100 joint research projects so far.

EMPIR (Article 185 and H2020 funding schemes) inside EURAMET is issuing calls, including Environmental metrology. As several EMSODEV partners are participating in these initiatives, the consortium will be informed of the new tentative standards and launch updates of the EGIM procedures.

\section{4) Same data format and access}

Addressed by other developments from EmsoDev.

\section{EGIM description}

The EGIM prototype is $1.300 \mathrm{~mm}$ high, $850 \mathrm{~mm}$ in diameter and the weight in air is $130 \mathrm{daN}$. It is rated up to 4850 meters due to some sensors pressure limit but some instruments are qualified for $6000 \mathrm{~m}$ depth.
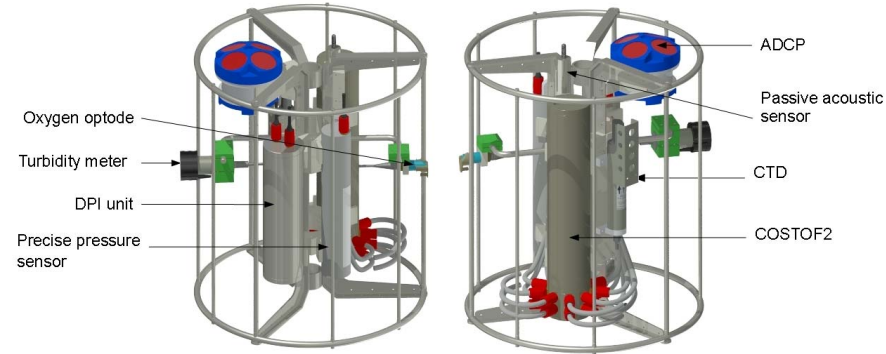

FIG. 4 EGIM INSTRUMENTS

a) The core sensors

A first set of seven sensors were selected for the first units: a CTD, a precise pressure gauge, an oxygen optode, a turbidity meter, an ADCP $300 \mathrm{kHz}$ and a hydrophone.

The positioning, the orientation and the correct mechanical setting of the sensor ensure its optimal performance:

The instruments are placed 1 meter above the seafloor, facing head down, in the water flow except for those equipped with a pumping device.

The space in front of the optical windows are free from obstructions in order to avoid any interference with measurements.

The ADCP can be placed facing upwards, downwards for surface deployment, vertical with respect to the seabed. In all cases, it is installed away from any protusions that could reflect 
ADCP energy, in order to allow a reflexion-free clearance of $15^{\circ}$ around each beam.

The acoustic sensor is installed higher than the frame as far as possible from any protusions that could shadow wave spreading.

\section{b) The electronic core, COSTOF2}

COSTOF2, COmmunication and STOrage Front-end, 2nd generation is the electronic core recently developed by Ifremer, already proven in deployment at sea [6], and presenting an optimal innovation / reliability ratio.

COSTOF2 was primarily designed for non-cabled applications, hence perfectly matches the requirements and constraints of the standalone EMSO nodes.

In the case of cabled nodes, COSTOF2 may be operated as a transparent junction box between shore and sensors, with the option of sensor drivers on shore. The main advantage of extending its use to cabled EMSO nodes is to have a unique reference for all nodes, an important step towards standardization, increasing global reliability and reducing costs across EMSO.

Furthermore, in the case of power and/or Ethernet link short-term failure, COSTOF2 takes control of the EGIM, switching from cabled to non-cabled mode in order to help maintaining data series continuity and finally to a secure mode with the sensors switched off and the system in a sleep state. On a regular basis, the COSTOF2 tests the connection to the node in terms of power and Ethernet and attempts to return to nominal (cabled) mode.

\section{c) The Data\&Power converter unit}

For 300-400V DC cabled installations, the Data\&Power Interface ensures the node power voltage conversion to 30 VDC and can host an optical to Ethernet converter. It also provides energy to the EGIM in case of power loss.

\section{d) The modular frame}

The EGIM frame protects the components and maintains them in the appropriate place before and during deployment. The EGIM is not generally intended to be used dismounted from its frame, added as a whole to a mooring, a node or an external frame.

The EGIM frame is made of titanium. The core is made up of 3 "C" shape central parts molded together. This set withstands all the mechanical efforts that it can be exposed to and can be attached at the top or at the bottom to any external frame. The central space should be the interface for the pin used on moorings. The rings and the beams are removable and exchangeable.

\section{e) Batteries for stand alone deployments}

For standalone applications, the EGIM can be powered by lithium battery packs delivering a $28 \mathrm{~V}$ DC nominal voltage.

\section{SERVICES PROVIDED}

The EGIM provides all the services required to ensure the best measurement quality and long-term working according to the Best Practices Handbook by FIXO3 and ESONET-EMSO Label, those services being:

- Power distribution and temporary power backup.

- Immersion, positioning, orientation and proper mechanical setting of the sensor.

- Measurement data backup and storage.

- Data time stamping with a clock common to the sensors, with high precision where necessary: For most applications (drift less than 1 minute/year), a temperature compensated crystal oscillator for classic applications ensures a precision of $\pm 2 \times 10-6$. A high precision embedded atomic clock is available for specific sensor (seismometers, hydrophones...) requirements. It assures a precision of $\pm 5.0 \times 10-11$ and a drift less than $1.5 \mathrm{~ms} /$ year. A pre deployment GPS synchronization (NMEA + PPS) is required, with capability to measure clock drift after recovery.

- Protection against the environment, once installed and during deployment/recovery operations.

- Protection against fouling: The CTD and the oxygen sensor are protected with chlorination antifouling. EGIM prototype has a built-in capability of active chlorination antifouling available and the ability to manage other active antifouling devices.

- Bi-directional communication services: high bandwidth capabilities for in-situ WiFi and cabled configuration link (Ethernet), and optimized communication protocols for satellites, inductive or acoustic links and autonomous mode.

- Remote control and configuration of EGIM parts: realtime access to the technical parameters such as storage space, continuous measurement, power consumption.

- Functioning mode self-management in case of power and/or Ethernet link loss.

\section{DEPLOYMENTS}

Operating modes, power requirements, mechanical design, embedded software enable the EGIM to adapt to the various EMSO node configuration: mooring line, sea bed station, cabled or non-cabled and surface buoy.
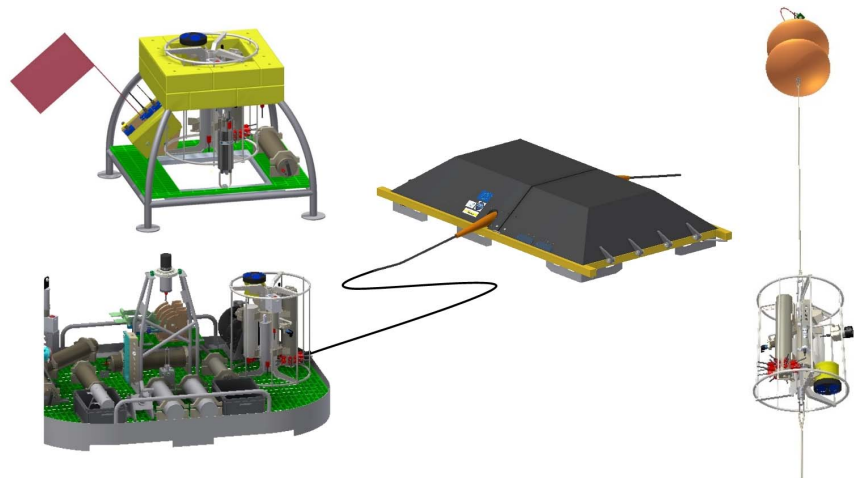

FIG. 5 EGIM IN EXAMPLES OF AUTONOMOUS, CABLED AND MOORING CONFIGURATION 


\section{CONCLUSION}

The EGIM is multi-purpose and matches all the EMSO site and discipline specific requirements. Its compact and modular nature allows for flexible deployment scenarios that include being able to accommodate new instruments. This will be a key point to the modularity, inter-operability and capacity of the future evolution of the system.

Having the EGIM as the sole reference for all nodes is a crucial step towards standardization, increasing global reliability and reducing costs across EMSO.

The prototype unit was deployed for tests on OBSEA [7]. In September 2017, three unit of the EGIM will be deployed on EMSO-Azores [6], Plocan [8], and Catania [9].

The Marine Strategy Framework Directive (MSFD : 2008/56/EC) requires that Member States take measures to achieve or maintain Good Environmental Status (GES) by 2020. Marine monitoring (as the systematic measurement of biotic and abiotic parameters of the marine environment) is crucial and the EGIM measures parameters that are fundamental to understanding the good environmental status such as temperature, depth, salinity, turbidity, currents, noise and oxygen. With the increased pressure of human activities on the deep-sea, the EGIM is expected to be a tool for baseline monitoring on areas as pre and post human impact.

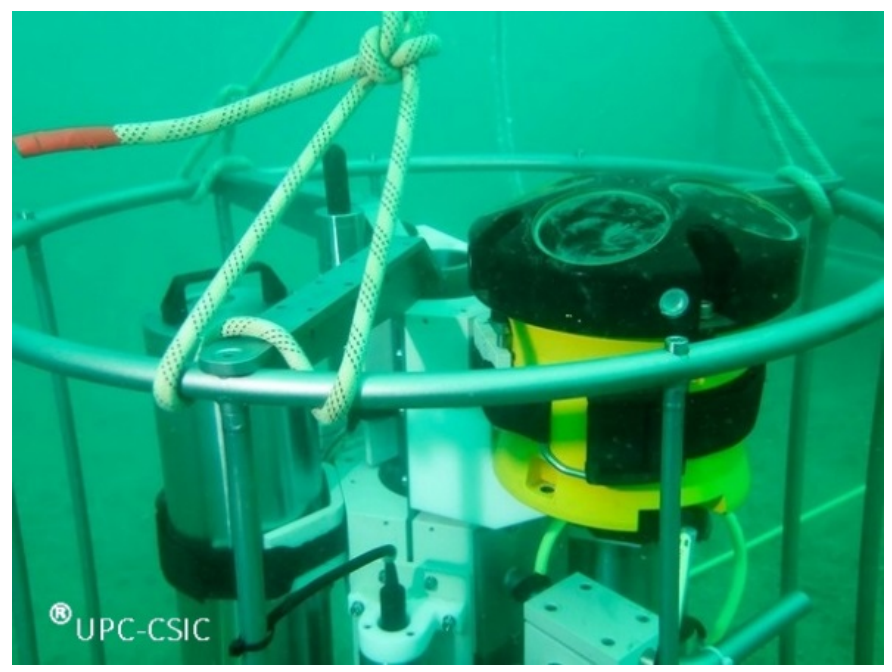

FIG. 6 EGIM DEPLOYED ON OBSEA

\section{ACKNOWLEDGMENT}

The European commission.

All the scientific colleagues of EmsoDev for their specification of the first EGIM features.

All engineers of EmsoDev for the design, development, testing of the EGIM Prototype.

\section{REFERENCES}

[1] Ruhl, Henry A.; André, Michel; Beranzoli, Laura; Ça?atay, M. Namik; Colaço, Ana; Cannat, Mathilde; Dañobeitia, Juanjo J.; Favali, Paolo; Géli, Louis; Gillooly, Michael; Greinert, Jens; Hall, Per O.J.; Huber, Robert; Karstensen, Johannes; Lampitt, Richard S.; Larkin, Kate E.; Lykousis, Vasilios; Mienert, Jürgen; Miguel Miranda, J.; Person, Roland; Priede, Imants G.; Puillat, Ingrid; Thomsen, Laurenz; Waldmann, Christoph. 2011 Societal need for improved understanding of climate change, anthropogenic impacts, and geo-hazard warning drive development of ocean observatories in European Seas. Progress In Oceanography, 91 (1). 1-33.10.1016/j.pocean.2011.05.001

[2] European Commission, G. Technology Readiness Levels (TRL), "Technology readiness levels (TRL)".HORIZON 2020 - WORK PROGRAMME 2014-2015 General appendixes, Extract from Part 19 Commission Decision C(2014)4995.

[3] ESONET deliverable D68 "Label definition" http://wwz.ifremer.fr/esonet_emso/content/download/42247/574588/file Deliverable D68 esonet-label-definition 1.0.pdf

[4] NF-XP X 10-812: Marine environment - Oceanographic instrumentation - Guide for environmental tests

[5] Handbook of best practices for open ocean fixed observatories http://hdl.handle.net/11329/302

[6] EMSO-Azores, http://www.emso-fr.org/EMSO-Azores

[7] OBSEA, http://www.fixo3.eu/observatory/OBSEA/

[8] PLOCAN, http://www.plocan.eu/index.php/es/

[9] CATAGNA, http://www.fixo3.eu/observatory/NEMO-SN1/ 